\title{
LYMPHANGIOGRAPHY AND CHROMOSOME STUDIES IN FEMALES WITH LYMPHOEDEMA AND POSSIBLE OVARIAN DYSGENESIS
}

\author{
BY \\ P. F. BENSON, M. H. GOUGH, and P. E. POLANI \\ From the Paediatric Research Unit, Guy's Hospital Medical School, and the \\ Professorial Surgical Unit, St. Thomas's Hospital Medical School, London
}

(RECEIVED FOR PUBLICATION JULY 24, 1964)

In primary lymphoedema, lymphangiography has revealed abnormalities of the lymphatics. Kinmonth (1960), in a series of 192 patients, found hypoplasia of the lymphatic trunks in $65 \%$, aplasia in $15 \%$, varicose dilatation in $14 \%$, and backflow of dye into the lymphatic dermal plexus in $6 \%$. These findings suggested that primary lymphoedema was due to congenital error in the development of lymphatics.

Congenital peripheral oedema occurs in a proportion of patients with ovarian dysgenesis and allied disorders. A history of oedema was obtained in 45 out of 126 patients $(35.7 \%)$ under the age of 16 , but only in 4 of $120(3.3 \%)$ over the age of 16 (Bishop, Lessof, and Polani, 1960); it was present in 9 of the $51(17 \cdot 6 \%)$ patients reported by Lindsten (1963).

The course of oedema in ovarian dysgenesis differs from that of other types of lymphoedema. Thus in primary lymphoedema, oedema is stationary or slowly progressive, while in ovarian dysgenesis it disappears in a few months or years in the majority of cases. Occasionally, however, it persists or recurs at puberty or after administration of oestrogens or anabolic steroids.

In this article we report the result of lymphangiography and chromosomal analysis in six patients with lymphoedema who were phenotypically female and who had clinical evidence of ovarian dysgenesis. Lymphangiography was carried out at St. Thomas's Hospital. Recent advances in the technique of lymphangiography have been published elsewhere (Gough, Guiney, and Kinmonth, 1963) and will not be repeated here. The chromosome analysis, after blood or skin culture, was carried out by one of us (P.E.P.) with the help of other members of the cytogenetics section of the Paediatric Research Unit, Guy's Hospital Medical School.

\section{Cases}

Case 1. (P.R.U. 794). Phenotypic female with congenital lymphoedema of hands and feet, webbing of neck. Sex chromosomes XO. Hypoplasia of lymphatic trunks of feet and of superficial lymphatics of legs. Anomalous lymph vessels at ankles.

Congenital pitting oedema of hands and feet gradually subsided and disappeared by 3 years. She had been born after a normal pregnancy and delivery, weighing 2,800 g. Her parents and sister were healthy. The diagnosis of mild congenital hypertrophic pyloric stenosis was suspected clinically and supported by visualization of an elongated pylorus on barium meal studies. A brother had had congenital hypertrophic pyloric stenosis, confirmed at operation, and another brother had had the same condition diagnosed on clinical grounds. Her toe-nails were hypoplastic and she had webbing of the neck. At 9 months of age, she was $65.5 \mathrm{~cm}$. tall (3rd percentile) and weighed $6.6 \mathrm{~kg}$. (less than $3 \mathrm{rd}$ percentile).

Chromosomes: number 45; sex chromosomes complement XO; chromatin negative on nuclear sexing.

LYMPHANGIOGRAPHY. At 2 years and 10 months, incisions were made on the dorsum of each foot. A fine spongy network of lymphatics was seen in the subcutaneous tissue. Biopsy of this tissue confirmed the presence of multiple minute lymph vessels without valves. In the normal subject at this site there are three or four small discrete lymphatic vessels running in the subcutaneous tissue, immediately below the skin.

Further incisions were made in the skin over the dorsum of the ankles. On the left, several larger but abnormal lymphatics were seen that were too small to cannulate. On the right there were several vessels running superficial to the deep fascia before piercing it. In spite of the quantity of patent blue in the subcutaneous lymphatic plexus, these deep vessels were only slightly coloured, suggesting a poor circulation between the superficial and deep lymphatic systems. With the aid of a dissection microscope, a size 30 hypodermic needle was inserted in one of the vessels on the deep fascia, and $3.5 \mathrm{ml}$. of ultrafluid Lipiodol (Bengue) were injected. 

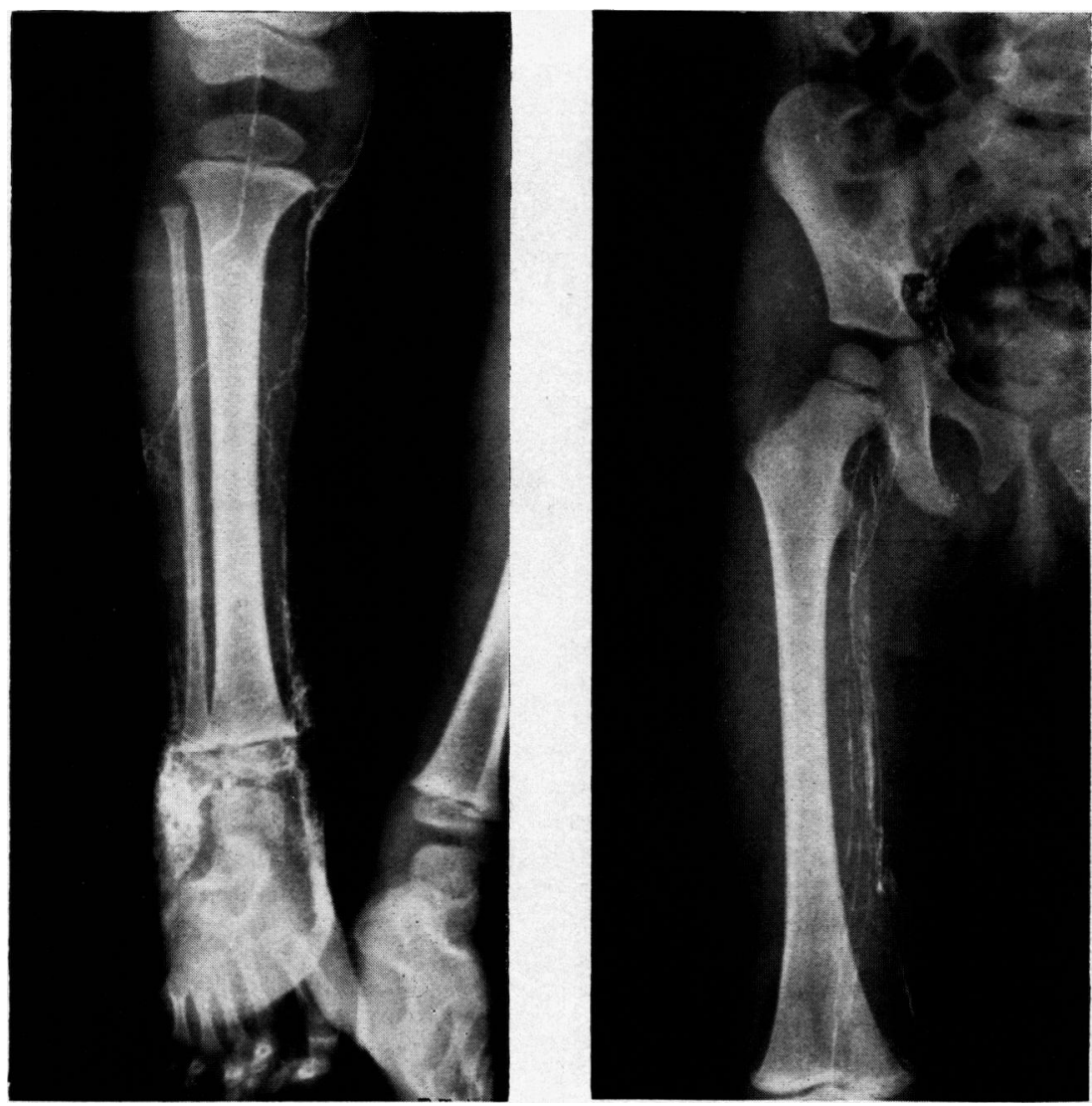

FIG. 1a and b.-X-ray lymphangiogram (Case 1) showing hypoplasia of superficial lymphatics with early filling of deep lymphatic vessels in leg and thigh. Aplasia of superficial inguinal glands. Compare normal lymphangiogram in Fig. 2.

Radiographs (Fig. 1a and b) showed contrast medium in the superficial plexus of the foot and lower leg, which, unlike those of the normal subject (Fig. 2), drained through the deep fascia to an apparently normal deep lymphatic system.

Case 2. (P.R.U. 144). Phenotypic female with congenital lymphoedema of feet. Sex chromosomes XO. Hypoplasia of lymphatics of right leg, left leg not explored.

Congenital pitting oedema of both feet, gradually subsided and disappeared by 4 years of age. She had been born after a normal pregnancy and delivery at full term, weighing $2,800 \mathrm{~g}$. She was an only child of healthy parents. Hypoplasia of big toe-nail and aplasia of other toz-nails. Finger-nails were flat and on the left hand were spoon shaped. An intravenous pyelogram at 2 months of age showed bilateral bifid renal pelvis. The cardiovascular and other systems were normal. At 5 years 7 months, she was $103 \mathrm{~cm}$. tall (5th percentile) and weighed $19 \cdot 1 \mathrm{~kg}$. (25t'l percentile).

Chromosomes: number 45 ; sex chromosomes complement XO; chromatin negative on nuclear sexing.
LYMPHANGIOGRAPHY. At 10 months of age, marked hypoplasia of the lymphatic tracts of the right leg was present, both on the dorsum of the foot and at the anterior aspect of the ankle. The left leg was not explored.

Case 3. (P.R.U. 393). Phenotypic female with congenital lymphoedema of hand and feet. Sex chromosomes XO. Aplasia of lymphatics of the left leg and right foot. Hypoplasia of right leg.

Congenital pitting oedema of right hand and both feet. Swelling of hand cleared by 9 months, but feet were still swollen at 3 years. She had been born at 44 weeks after normal pregnancy and delivery, weighing $3,200 \mathrm{~g}$. The parents, brother, and sister were healthy. There was hypoplasia of the toe-nails. The cardiovascular and other systems were normal. When 33 months of age, she was $84 \mathrm{~cm}$. tall (less than $3 \mathrm{rd}$ percentile) and weighed $12 \cdot 7 \mathrm{~kg}$. (25th percentile).

Chromosomes: number 45; sex chromosomes complement $\mathrm{XO}$; chromatin negative on nuclear sexing. 


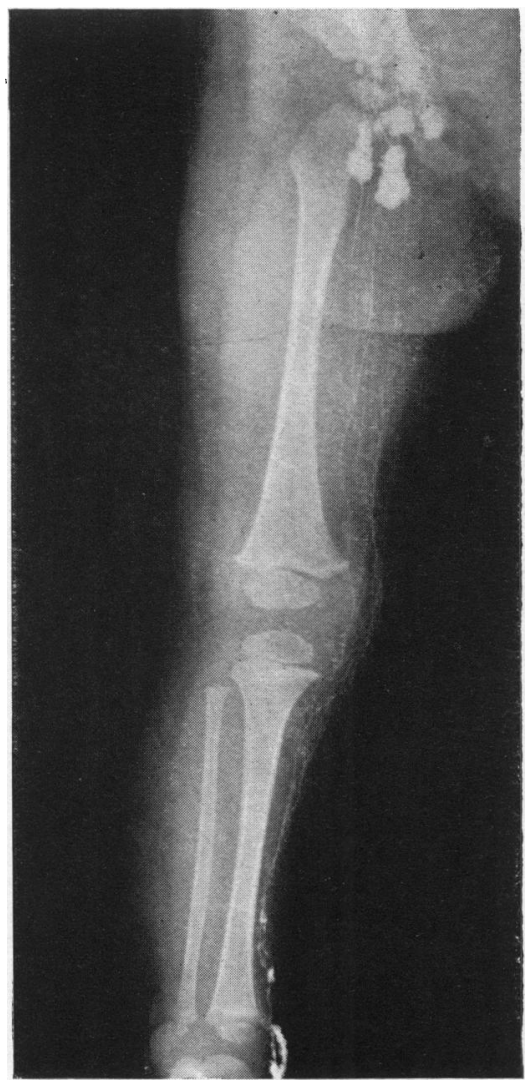

FIG. 2.-The appearance of normal superficial lymphatic trunks in child aged 5 months. Note filling of superficial lymphat ic vessels and of superficial inguinal nodes.

LYMPHANGIOGRAPHY. At 2 years of age, no lymphatics were seen on the left side, either on the dorsum of the foot or at the ankle. No lymphatics were seen on the dorsum of the right foot, but a few hypoplastic vessels were present on the anterior aspect of the right ankle.

Case 4. (P.R.U. 1241). Phenotypic female with congenital lymphoedema. Sex chromosomes XO. Aplasia of lymphatics of left foot. Extreme hypoplasia of lymphatics of right foot.

Congenital lymphoedema of both feet and legs. The swelling on the left side was still present at 4 years of age, while on the right it had disappeared by 6 months. Her toe-nails were hypoplastic. She had been born at full term after a pregnancy complicated by pyelitis at 4 months. Her birth weight was $4 \cdot 3 \mathrm{~kg}$. Her parents and sister were healthy.

Chromosomes: number 45 ; sex chromosomes complement XO; chromatin negative on nuclear sexing.

LYMPHANGIOGRAPHY. At 3 years of age, dermal backflow occurred into vesicles below the left external malleolus. At exploration, no lymphatic tracts were seen on the dorsum of the left foot. On the dorsum of the right foot, a network of minute subcutaneous lymphatic tracts was seen. Some very small lymphatic tracts were seen at the ankle, which could not be cannulated.

Case 5. (P.R.U. 317). Phenotypic female with bilateral congenital lymphoedema of hands and feet. Coarctation of aorta, webbing of neck. Sex chromosomes $X O$. Aplasia of lymphatics of feet and hypoplasia of superficial lymphatic vessels of legs. Anomalous lymphatic trunks of ankles.

Congenital symmetrical lymphoedema of hands and feet, still present at $2 \frac{1}{2}$ years. Her parents and brother were healthy. She was born after a normal pregnancy and delivery weighing $2,800 \mathrm{~g}$. She had probable coarctation of the aorta, moderate webbing of the neck, bilateral epicanthic folds, and hypoplastic nails. At 15 months of age, she was $81 \mathrm{~cm}$. tall (90th percentile) and weighed $11.8 \mathrm{~kg}$. (85th percentile).

Chromosomes: number 45 ; sex chromosomes complement XO; chromatin negative on nuclear sexing.

LYMPHANGIOGRAPHY. At 2 years and 8 months of age, dermal backflow occurred in both feet. No lymph vessels were seen through dorsal incisions in both feet. The subcutaneous tissue was spongy and vascular. At the ankles, the appearance was similar to that in Case 1, there being a few anomalous lymphatic vessels that were seen to pierce the deep fascia. These were too small for injection of radio-opaque material.

Case 6. (P.R.U. 1422). Phenotypic female with congenital lymphoedema of both feet, double harelip, cleft palate, no secondary sexual characteristics, and primary amenorrhoea. Moderate webbing of the neck. Sex chromosomes $X Y$. Hypoplasia of lymphatics of feet and ankles.

Bilateral congenital lymphoedema of feet and legs which fluctuated in severity but persisted until last seen when she was 22. The father was healthy, but the mother, whose menarche had not occurred until the age of 20 , had had a hysterectomy for oophoritis. The patient's sister had menarche at 17. There were no brothers. She had double harelip and complete cleft palate. She had never had any vaginal bleeding. At 20 years, an infantile uterus was felt rectally. There was no pubic or axillary hair and no development of breasts and nipples. There was moderate webbing of the neck, incurving of the fifth finger of the right hand, epicanthic folds and a soft basal cardiac systolic murmur, but no other abnormality of cardiovascular or other systems. At 21 years of age, she was $159 \mathrm{~cm}$. tall and $24 \mathrm{~kg}$. in weight. She was treated with ethinyl oestradiol $0.1 \mathrm{mg}$. daily three weeks out of four. Cyclical vaginal bleeding occurred and was accompanied by increase in weight and aggravation of oedema.

Chromosomes: number 46; sex chromosomes complement XY; chromatin negative on nuclear sexing.

LYMPHANGIOGRAPHY. Bilateral lower limb lymphangiography was performed under general anaesthetic at 20 years of age. Patent Blue was injected interdigitally 


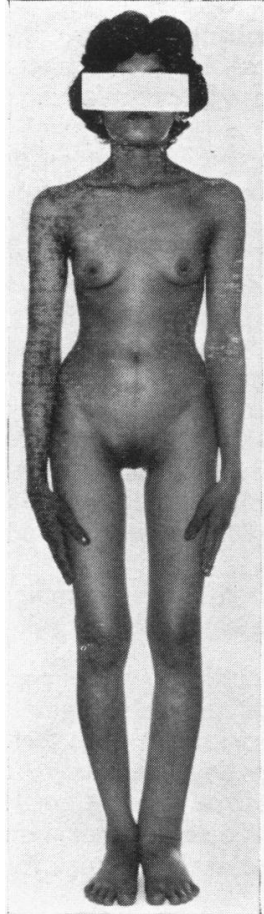

FiG. 3.-Case 7, aged 21. Normal development of breasts and nipples, scanty pubic hair, lymphoedema left leg.

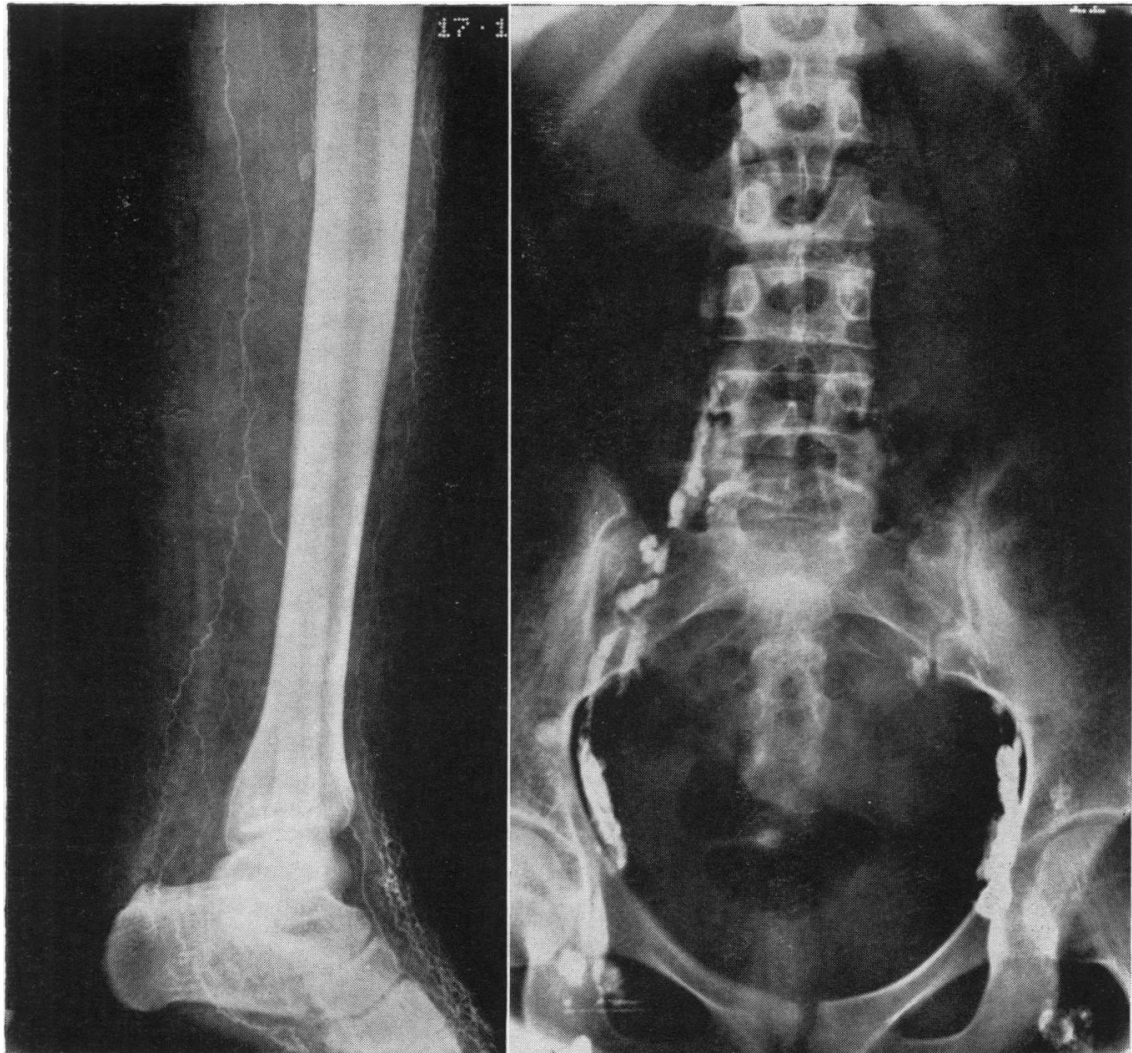

FIG. 4a and b.-X-ray lymphangiogram (Case 7) showing many small tortuous channels in left foot and calf, typical of distal obstruction. No filling of left common iliac or left para-aortic lymph nodes. in each foot. There was an almost immediate appearance of dye in the dermal lymphatic plexus ('dermal backflow'), more pronounced on the right than the left. Exploration of the dorsum of both feet and ankles revealed extreme hypoplasia of the lymphatic trunks.

Radiographs after induction of pneumoperitoneum at 21 years of age confirmed the presence of a small uterus, but no ovaries were demonstrated.

Case 7. (P.R.U. 1139). Phenotypic female. No axillary and scanty pubic hair. Absent uterus. Acute onset of lymphoedema of left leg. Hypoplasia of lymphatics of left foot and leg. Aplasia of left common iliac and para-aortic lymph nodes. Sex chromosomes $X Y$.

This girl from British Guiana was healthy until 7 years of age when she developed pain, redness, and swelling of her left leg below the knee. The onset was abrupt and cellulitis was diagnosed. Pain subsided over a few weeks and she was left with swelling. At 18 years of age, she had had vaginal bleeding on one occasion following intercourse. No further bleeding had occurred during the next three years. Her parents and one brother were healthy, but details of other relatives were unavailable.
At 21 years of age, she was $155 \mathrm{~cm}$. tall. Axillary hair was absent. There was scanty pubic hair, but otherwise the appearance of the external genitalia was that of a normal female. Breasts were developed, with normal development of nipples (Fig. 3). The uterus was not felt either during routine examination or under a general anaesthetic by Mr. K. J. R. Cuthbert, who found that the vagina ended blindly with a small area of thickening where one would expect the cervix to be. Reaching up from this, only a thin cord of tissue but no gonads could be felt.

No abnormality was present in her cardiovascular or other systems, her blood pressure being $140 / 80 \mathrm{~mm}$. $\mathrm{Hg}$.

Chromosomes: number 46 ; sex chromosomes complement XY; chromatin negative on nuclear sexing.

LYMPHANGIOGRAPHY. This was performed at 20 years of age. There was dermal backflow on the dorsum of the left foot, ankle, and calf. Dye was seen in the dermal plexus through an incision in the dorsum of the foot, but only two subcutaneous lymphatic tracts were seen, one normal in size and the other small. Ultrafluid Lipiodol was injected into the larger of the two tracts. Subsequent 
TABLE 1

RELATION OF CLINICAL FEATURES TO FINDINGS ON LYMPHANGIOGRAPHY AND TO SEX CHROMOSOMES COMPLEMENT

\begin{tabular}{|c|c|c|c|c|c|}
\hline $\begin{array}{l}\text { Case } \\
\text { No. }\end{array}$ & $\begin{array}{l}\text { Dist ribution } \\
\text { of Oedema }\end{array}$ & Course of Oedema & Other Features & $\begin{array}{l}\text { Sex } \\
\text { Chromo- } \\
\text { somes }\end{array}$ & Lymphangiography \\
\hline 1 & Hands and feet & Disappeared by 3 yr. & $\begin{array}{l}\text { Congenital pyloric stenosis, } \\
\text { webbing of neck }\end{array}$ & XO & $\begin{array}{l}\text { Hypoplasia of superficial } \\
\text { lymphatic vessels in both } \\
\text { legs and feet; anomalous } \\
\text { vessels }\end{array}$ \\
\hline 2 & & Disappeared by 4 yr. & Bifid pelvis both kidneys & XO & $\begin{array}{l}\text { Hypoplasia right leg, left } \\
\text { leg not explored }\end{array}$ \\
\hline 3 & $\begin{array}{l}\text { Right hand and } \\
\text { feet }\end{array}$ & $\begin{array}{l}\text { Still present in feet at } 3 \\
\text { yr. }\end{array}$ & - & XO & $\begin{array}{l}\text { Aplasia left leg and right } \\
\text { foot, hypoplasia right leg }\end{array}$ \\
\hline 4 & Feet & $\begin{array}{l}\text { Right side disappeared } \\
\text { at } 6 \mathrm{mth} \text {; ; left side }\end{array}$ & - & XO & $\begin{array}{l}\text { Aplasia left foot; hypo- } \\
\text { plasia right foot and leg }\end{array}$ \\
\hline 5 & Hands and feet & Present at $30 \mathrm{mth}$. & $\begin{array}{l}\text { Coarctation, webbing of } \\
\text { neck, epicanthic folds }\end{array}$ & XO & $\begin{array}{l}\text { Aplasia both feet, hypo- } \\
\text { plasia both legs; anoma- } \\
\text { lous vessels }\end{array}$ \\
\hline 6 & Feet & Still present at $22 \mathrm{yr}$. & $\begin{array}{l}\text { Double harelip, cleft } \\
\text { palate, primary amenor- } \\
\text { rhoea, no secondary } \\
\text { sexual characteristics }\end{array}$ & $\mathbf{X Y}$ & $\begin{array}{l}\text { Extreme hypoplasia both } \\
\text { feet and ankles }\end{array}$ \\
\hline 7 & Left leg & Still present at $21 \mathrm{yr}$. & $\begin{array}{l}\text { Absent uterus, absent } \\
\text { axillary hair, scanty } \\
\text { pubic hair, breasts } \\
\text { developed }\end{array}$ & $\mathbf{X Y}$ & $\begin{array}{l}\text { Hypoplasia left foot and } \\
\text { leg; aplasia lymphatic } \\
\text { left common iliac and } \\
\text { left para-aortic lymph } \\
\text { nodes }\end{array}$ \\
\hline
\end{tabular}

radiographs (Fig. 4a), showed many small tortuous channels in the left foot and calf. The external iliac lymph nodes filled normally, but neither the left common iliac nor the left para-aortic glands had filled at either 2 or 24 hours (Fig. 4b). On the right side, lymphatic tracts appeared normal both visually and radiographically.

\section{Discussion}

Results of our study are summarized in Table 1. All patients had hypoplasia or aplasia of the superficial lymphatic tracts of the lower limbs. In addition, two patients (Cases 1 and 5) had anomalous lymphatic channels in the ankles running on the outer aspect of the deep fascia before piercing it. After subcutaneous injection of Patent Blue in the interdigital spaces of the foot, these anomalous vessels were only a pale shade of blue in contrast to the deep colour observed in normal vessels. Subsequent radiographs of the lower limb showed filling of the deep lymph vessels (Fig. 1a and b), but not of the superficial trunks which are visualized in the normal subject (Fig. 2).

Obstructed lymphatic drainage due to congenital hypoplasia of the superficial lymphatic channels appears therefore to be a factor in the production of oedema in patients with gonadal dysgenesis. It is tempting to suggest that the presence of anomalous lymphatic channels connecting the hypoplastic superficial channels to the deep lymphatic system such as were demonstrated in two of our patients, may be a factor in the disappearance of oedema in the majority of patients with ovarian dysgenesis. Delayed or poor uptake of subcutaneous dye by the anomalous vessels, however, suggested that their compensating capacity was incomplete.

The cyclical increase of oedema while on periodic oestrogen therapy suggests that fluid retention may be another factor. Fluid retention is known to occur in women with normal ovarian function. During the menses, it may lead to oedema in normal women or to aggravation of oedema in women with primary lymphoedema.

An XO sex chromosomal complement was found in Cases 1-5, such as is found in the majority of patients with gonadal dysgenesis (Polani, 1961). Details of the cytological findings are in Table 2. In Case 6, the XY sex chromosomal complement was confirmed by blood cultures, and in Case 7 by both blood and skin cultures which failed to show any evidence of chromosome mosaicism. Testicular feminization syndrome was considered in the differential diagnosis of these two patients. In Case 6 , the existence of associated congenital abnormalities, the presence of a uterus with occurrence of uterine bleeding during periodic oestrogen therapy and absence of family history militate against this diagnosis. However, in Case 7, the diagnosis of testicular feminization syndrome seems possible (see addendum). No uterus could be palpated at an examination under general anaesthesia, and there was definite breast development. The family history was incompletely known. We have been unable to find a previous report of lymphoedema occurring in testicular feminization syndrome.

The seven patients described in this paper were selected because they exhibited at least some of the 
TABLE 2

RESULTS OF CHROMOSOMAL ANALYSIS

\begin{tabular}{|c|c|c|c|c|c|c|c|c|c|}
\hline \multirow{3}{*}{$\begin{array}{l}\text { Case } \\
\text { No. }\end{array}$} & \multirow{3}{*}{$\begin{array}{l}\text { Sex Chromatin } \\
\text { (oral smear) }\end{array}$} & \multirow{2}{*}{\multicolumn{2}{|c|}{$\begin{array}{l}\text { No. of Tissue } \\
\text { Investigations }\end{array}$}} & \multicolumn{6}{|c|}{ Chromosomes } \\
\hline & & & & \multicolumn{5}{|c|}{ Count Distribution } & \multirow{2}{*}{$\begin{array}{c}\text { Sex } \\
\text { Chromosomes }\end{array}$} \\
\hline & & $\begin{array}{l}\text { Blood } \\
\text { Culture }\end{array}$ & $\begin{array}{l}\text { Skin } \\
\text { Culture }\end{array}$ & $\begin{array}{c}\text { Total Cell } \\
\text { Count }\end{array}$ & $<45$ & 45 & 46 & $>46$ & \\
\hline $\begin{array}{l}2 \\
3 \\
4 \\
5 \\
6 \\
7\end{array}$ & $\begin{array}{l}\text { Negative } \\
\text { Negative } \\
\text { Negative } \\
\text { Negative } \\
\text { Negative } \\
\text { Negative } \\
\text { Negative }\end{array}$ & $\begin{array}{l}4 \\
2 \\
2 \\
1 \\
2 \\
2 \\
2\end{array}$ & $\begin{array}{l}1 \\
0 \\
0 \\
0 \\
0 \\
0 \\
\\
1\end{array}$ & $\begin{array}{l}70 \\
35 \\
68 \\
52 \\
51 \\
46 \\
62 \\
56 \\
38\end{array}$ & $\begin{array}{l}9 \\
7 \\
3 \\
2 \\
1 \\
1 \\
2 \\
2\end{array}$ & $\begin{array}{l}57 \\
28 \\
65 \\
50 \\
50 \\
45 \\
1 \\
2\end{array}$ & $\begin{array}{l}4 \\
- \\
- \\
- \\
60 \\
55 \\
34\end{array}$ & $\begin{array}{l}- \\
- \\
- \\
\overline{-} \\
\overline{-} \\
-\end{array}$ & $\begin{array}{l}\text { XO } \\
\text { XO } \\
\text { XO } \\
\text { XO } \\
\text { XO } \\
\text { XO } \\
\text { XY } \\
\text { XY } \\
\text { XY }\end{array}$ \\
\hline
\end{tabular}

clinical features of ovarian dysgenesis and therefore no estimate can be made from them of the prevalence of sex chromosomal abnormalities in an unselected population of patients with lymphoedema.

\section{Summary}

Seven phenotypic females with lymphoedema were investigated. Six were considered to have ovarian dysgenesis, the sex chromosomal complement being $\mathrm{XO}$ in five, and $\mathrm{XY}$, without evidence of chromosome mosaicism, in one. No diagnosis was made in the seventh patient, whose sex chromosome complement was XY.

All seven patients had hypoplasia or aplasia of the superficial lymphatic vessels of the legs. In addition, two patients had anomalous lymphatic vessels connecting the hypoplastic superficial lymphatic vessels to the deep system. It is tentatively suggested that these channels may contribute towards the disappearance of oedema in patients with gonadal dysgenesis.

We are grateful to Dr. R. C. Mac Keith for referring Cases 2 and 3, and to Dr. D. Morris for Case 1; to
Professor J. B. Kinmonth for allowing us to publish results of the lymphangiography; to Dr. F. Giannelli, Miss J. Northfield, and Dr. A. Taylor for their help in the chromosomal analysis, and to Miss M. McGuire for technical assistance with the cytological work.

\section{REFERENCES}

Bishop, P. M. F., Lessof, M. H., and Polani, P. E. (1960). Turner's syndrome and allied conditions. Memoirs of the Society for Endocrinology, 7, 162.

Gough, M. H., Guiney, E. J., and Kinmonth, J. B. (1963). Lymphangiography: New techniques and uses. Brit. med. J., 1, 1181.

Kinmonth, J. B. (1960). Some aspects of cardiovascular surgery. J. roy. Coll. Surg. Edinb., 5, 287.

Lindsten, J. (1963). The Nature and Origin of $X$ Chromosome Aberrations in Turner's Syndrome, p. 52. Almquist and Wiksell, Uppsala.

Polani, P. E. (1961). Turner's syndrome and aliied conditions. Brit. med. Bull., 17, 200.

\section{Addendum}

In Case 7, the diagnosis of testicular feminization syndrome has recently been confirmed. At laparotomy (Professor J. B. Kinmonth), bilateral abdominal testes were found to be connected to the trigonal area of the bladder by two tubular structures interpreted as vasa deferentia. There was no uterus. The gonads were removed after their nature had been identified by histological examination of frozan sections. 